\title{
MJSSM Editors among Top Scientists Cited Worldwide in Stanford List
}

\author{
Bojan Masanovic ${ }^{1,2}$
}

Affiliations: 'University of Montenegro, Faculty for Sport and Physical Education, Niksic, Montenegro, ${ }^{2}$ Montenegrosport, Podgorica, Montenegro

Correspondence: B. Masanovic, University of Montenegro, Faculty for Sport and Physical Education, Narodne omladine bb, 81400 Niksic, Montenegro. E-mail: bojanma@ucg.ac.me

\begin{abstract}
In ancient times, science was practiced only by the privileged, primarily because of its poor accessibility. However, the development of ICT has enabled modern man to make science much more accessible to him/ her. For that reason, today, there are many more scientists who are trying to change the world for the better with their activities. In the race for new knowledge and original discoveries, scientists want to be better than others. Different metrics are used to measure quality among scientists. Stanford University recently published an updated list of the best scientists in the world, which is considered one of the most prestigious. On a recently published list, three editors of Montenegrin Journal of Sports Science and Medicine: Yousef Saleh Khader, Sergej M. Ostojic and Stevo Popovic have been ranked among the world's top 2\% most-cited scientists in 2020 and the purpose of this editorial is to recognize and promote their scientific impact and scientific excellence.
\end{abstract}

Keywords: sport science, top scientists, Stanford, World, ranking

@MJSSMontenegro

THE WORLD'S TOP $2 \%$ SCIENTISTS IN STANFORD LIST

http://mjssm.me/?sekcija=article\&artid $=235$

Cite this article: Masanovic, B. (2022). MJSSM Editors among Top Scientists Cited Worldwide in Stanford List. Montenegrin Journal of Sports Science and Medicine, 11(1), 5-8. https://doi. org/10.26773/mjssm.220310

\section{Introduction}

In ancient times, science was practiced only by the privileged, primarily because of its poor accessibility. However, the development of ICT has enabled modern man to make science much more accessible to him/her. For that reason, today, there are many more scientists who are trying to change the world for the better with their activities. In the race for new knowledge and original discoveries, scientists want to be better than others. Different metrics are used to measure quality among scientists. One of the metrics significantly used to assess scientific impact and scientific excellence is citation. However, citations, although widespread, have many limitations. Namely, it is not enough to count quotes, but it is necessary to assess what quotes mean, that is, to know how they are interpreted correctly and to know how they can be misin- terpreted. It is very important to emphasize that there are several different databases of citations, and they are: "Google Scholar", "Scopus", "Web of Science" and others. The "Google Scholar" database gathers the entire Internet in one place and systematically processes all documents that have a scientific character, while the quality of these documents is not taken into account that is a huge limitation. On the other hand, the "Scopus" and "Web of Science" databases operate on a different principle, they only collect documents that have gone through an evaluation process and have a certain level of quality. Therefore, it is very important to overcome certain technical and essential problems and to ensure an objective ranking of scientists around the world when it comes to assessing scientific impact and scientific excellence

Stanford University recently published an updated list of the 
best scientists in the world (Baas et al., 2021), which is considered one of the most prestigious. Why? It is based on bibliometric information contained in one of the most relevant "Scopus" databases, and has processed more than 180,000 scientists (out of 8 million active scientists worldwide), from 22 scientific disciplines and 176 subfields. Added value is also a fact that a research team, led by Professor John Ioannidis, offered an objective solution to overcome the limitations outlined in the previous paragraph and devised indicators that included information on citations, an individual's scientific research output, co-authorship and a composite indicator (Ioannidis et al., 2016). On a recently published list, three editors of Montenegrin Journal of Sports Science and Medicine: Yousef Saleh Khader, Sergej M. Ostojic and Stevo Popovic have been ranked among the world's top $2 \%$ most-cited scientists in 2020 and the purpose of this editorial is to recognize and promote their scientific impact and scientific excellence.

\section{Contribution to the field}

As pointed out in the previous chapter, science has progressed drastically from ancient times to the present day. One of the greatest thinkers of modern times, Stephen Hawking, also spoke about the development of science. As early as the beginning of the 21st century, he pointed out that he believed that the coming century would be "the century of complexity" (cited in Hausken-Sutter, 2021). What exactly is that supposed to mean? Namely, speaking about the way that science will develop during the 21 st century, Stephen Hawking unequivocally pointed to the fact that scientists will increasingly concentrate on scientific ideas that increasingly rely on in theories of chaos, complex systems, fractal geometry, nonlinear dynamics, and quantum mechanics (Newell, 2001). He also pointed out that in this way, scientists will be able to better understand the phenomena that characterize dynamism and unpredictability, then multidimensionality and interconnectedness, where he classified human behaviour as one of the most important anthropological issues of modern times (Nevell, 2001; Salmon \& McLean, 2020). After a little more than two decades since Hawking's prediction, it is clear that his theses were correct, primarily because the theory of complexity is very popular today. Interestingly, it is particularly important in the field of sports and health sciences, and that addressing these very important issues when it comes to healthy lifestyles requires the integration of knowledge from different fields (Burvitz et al., 1994; Terpstra et. al., 2010). As early as the end of the 20th century, there was an initiative that promoted research that integrated knowledge from several different fields (Burvitz et al., 1994), as research questions that are too broad and so complex that answers could be sought, exclusively in the field of one scientific discipline. In this way, we come to interdisciplinary research in which different knowledge, or disciplinary knowledge, is integrated through the construction of a more comprehensive understanding of the phenomenon being studied (cited in Hausken-Sutter, 2021). Hence, sports sciences gain importance because teams of disciplinary experts from different fields are formed to monitor the pragmatic research process, each from its own disciplinary field, while the conclusions and recommendations for further research have interdisciplinary character.

Sports sciences as an academic field are a relatively young field, which emerged at the end of the 20th century on the basis of monodisciplines such as pedagogy, sociology, psychology, but also physiology, anatomy, biology, as well as economics, medicine and others. Although physical education as a forerunner of sports sciences dates back to earlier times, the emergence of sports sciences as an academic field is associated with the creation of a larger number of subdisciplines in the subject area. From its inception until today, sports sciences are developing rapidly and this is reflected in the fact that "over 25,000 is published annually in the field of sports sciences, and it is equal as in most natural and technical science disciplines (Popovic, 2018)“. Thus, sports sciences, like most other scientific fields, are also developed on the principles of recognizing creativity and modern thinking, where no one theory or discipline should be valued in relation to another (cited in Hausken-Sutter, 2021). These changes are also visible in the example of Montenegrin Journal of Sports Science and Medicine (MJSSM), which, over the last ten years, has developed into a modern and high-quality interdisciplinary journal in the field of sports sciences and medicine. Namely, this fact is confirmed by the latest Stanford list of the best scientists in the world for 2020, which includes three MJSSM editors. Yousef Saleh Khader was ranked at 10,251 place among the best scientists in the world for 2020, while Sergej M. Ostojic was ranked on 27,132 and Stevo Popovic was ranked on 145,073 place (Baas et al., 2021). It is interesting that all three mentioned editors belong to different monodisciplines. Namely, Yousef Saleh Khader works as a Professor of Epidemiology and Biostatistics and Sports Scientist at the Department of Community Medicine, Jordan University of Science and Technology and took his doctoral degree in Biostatistics (his personal "Scopus" profile is print screened in Picture 1; Yousef Saleh Khader, 2021); Sergej M. Ostojic works as a Professor of Biomedical Sciences and Sport Scientist at the Laboratory for Applied Physiology and Nutrition at the Faculty of Sports and Phys-

\section{Khader, Yousef Saleh}

(1) jordan University of science and Techinologr, Irbid, pondan

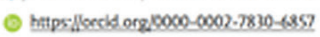

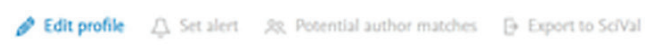
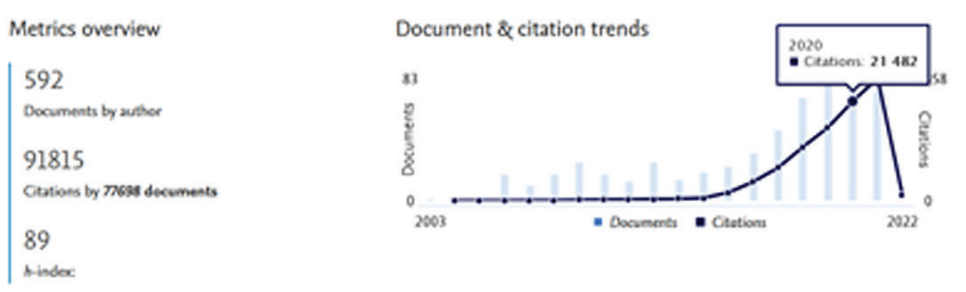

Most contributed Topics 2016-2020

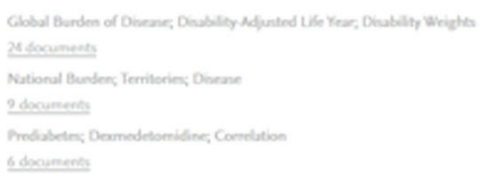

Figure 1. Personal "Scopus" Profile of Yousef Saleh Khader 


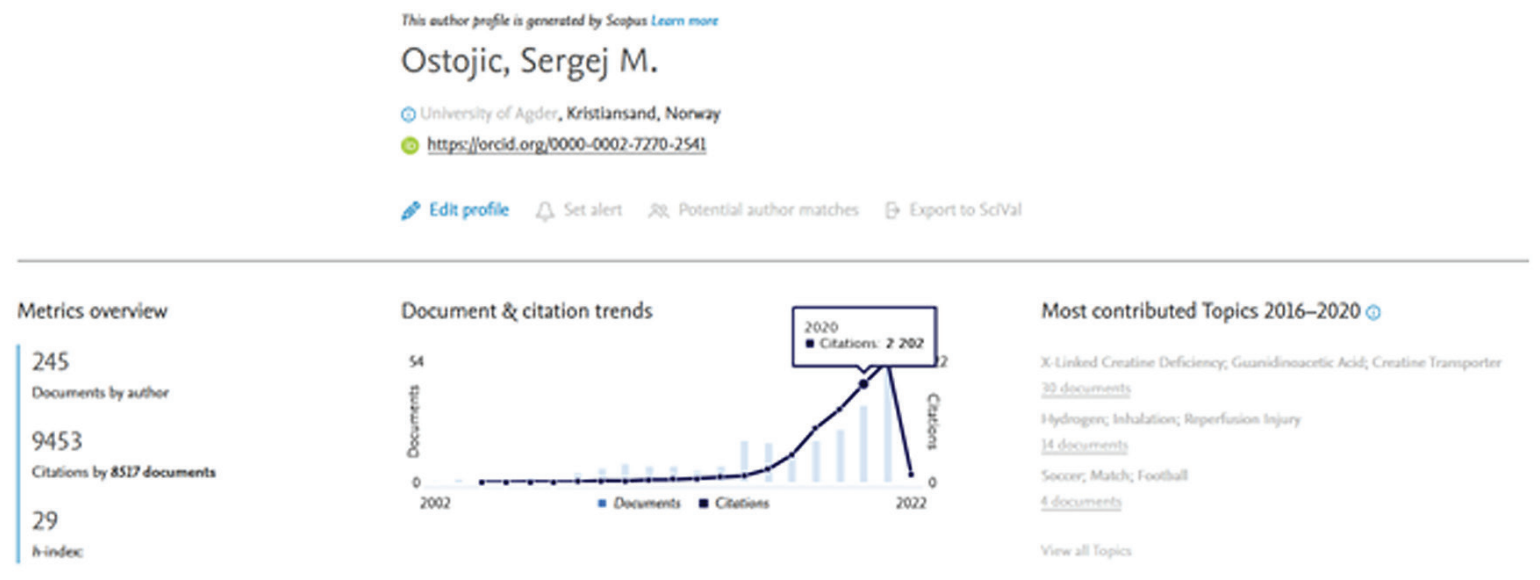

Figure 2. Personal "Scopus" Profile of Sergej M. Ostojic

ical Education, University of Novi Sad and took his doctoral degree in Medicine (his personal "Scopus" profile is print screened in Picture 2; Sergej M. Ostojic, 2021); while Stevo Popovic works as an Associate Professor of Sport Science and Sport Scientist at the Faculty for Sport and Physical Education at the University of Montenegro and took his doctoral degree in Sport Management (his personal "Scopus" profile is print screened in Picture 3; Stevo Popovic, 2021). Thus, MJSSM is a journal founded with the idea of developing the interdisciplinarity of sports sciences and brings together all scientists who aim to contribute to interdisciplinary teamwork with a holistic approach to sports and physical activity as well as all related areas.
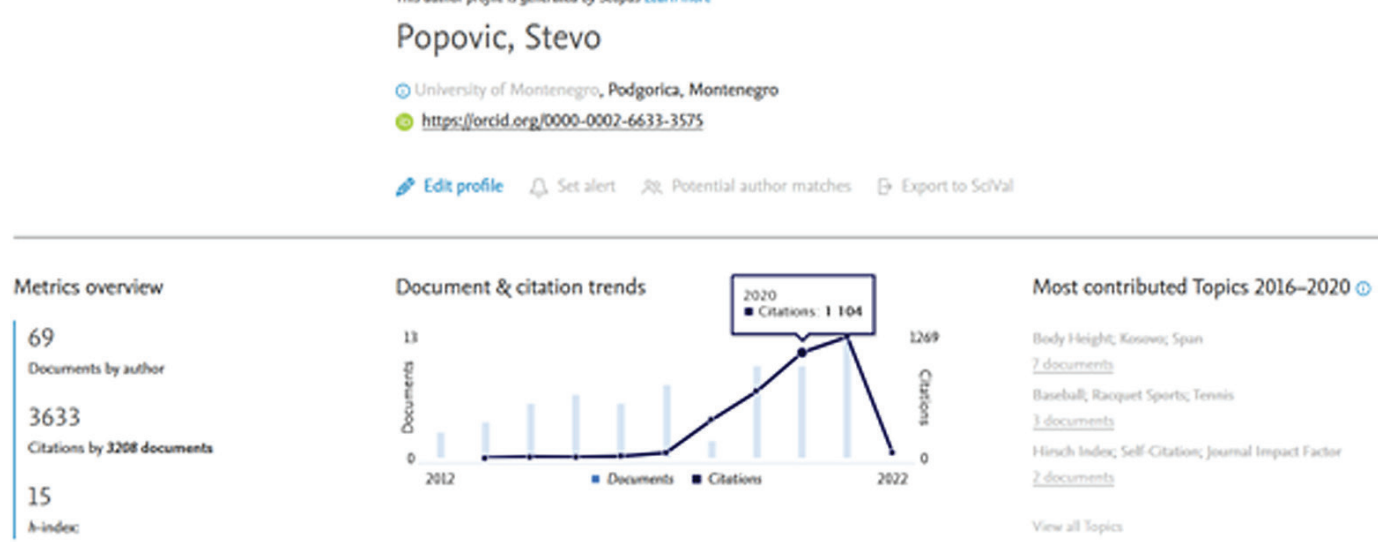

Figure 3. Personal "Scopus" Profile of Stevo Popovic

\section{Conclusion}

From all that has been mentioned so far, the fact is that interdisciplinarity is an important element of Sports Sciences. Interdisciplinarity is characterized by certain "forms": scientific, organizational, academic and social form (Camy et al, 2017), and all four forms must be recognized by a particular subject in order to be labelled as interdisciplinary. MJSSM strives to be an interdisciplinary journal in the field of Sports Sciences, and to cover all subdisciplines belonging to Sports Sciences and Medicine, such as Social Sciences and Humanities, Sports Medicine and Physiology, and Biomechanics and Neurophysiology, three areas that are most visible internationally (Champely et al., 2017). Although the sports sciences have strengthened as a separate academic field, it is still very difficult to talk about the clear boundaries that this field covers. Debates are still ongoing, especially in countries where Sports Sciences are less developed. The situation in Montenegro (where MJSSM is located) is better from year to year, primarily due to the rapid progress of the MJSSM, but also the Annual Scientific Conference of the Montenegrin Sports Academy and the growing number of young sports scientists who mature and become scientists recognized on the international scene. However, the biggest contribution was made by the last ranking list, which included three MJSSM editors, thus confirming the strong interdisciplinary character of MJSSM and the quality of human staff, which promise further growth of quality and recognition of MJSSM on the international scene.

\section{References}

Baas, Jeroen; Boyack, Kevin; Ioannidis, John P.A. (2021), "August 2021 data-update for "Updated science-wide author databases of standardized citation indicators"', Mendeley Data, V3. https://doi.org/10.17632/btchxktzyw.3 Burwitz, L., Moore, P. M., \& Wilkinson, D. M. (1994). Future directions for performance-related sports science research: an interdisciplinary approach. Journal of Sports Sciences, 12(1), 93-109.

Camy, J., Fargier, P., Perrin, C., \& Belli, A. (2017). Forms of interdisciplinarity in four sport science research centres in Europe. European journal of sport science, 17(1), 30-41. https://doi.org/10.1080/17461391.2016.1218551

Champely, S., Fargier, P., \& Camy, J. (2017). Disciplinarity and sport science in Europe: A statistical and sociological study of ECSS conference abstracts. European journal of 
sport science, 17(1), 5-18. https://doi.org/10.1080/174613 91.2016.1197318

Hausken-Sutter, S.E. (2021, September 22). Complexity and interdisciplinarity in sport science: a PhD student's perspective. Idrottsforum. https://idrottsforum.org/ feature-hauskensutter210922/

Ioannidis, J. P., Klavans, R., \& Boyack, K. W. (2016). Multiple Citation Indicators and Their Composite across Scientific Disciplines. PLoS biology, 14(7), e1002501. https://doi org/10.1371/journal.pbio.1002501

Newell, W.H. (2001). A theory of interdisciplinary studies. Issues in Integrative Studies, 19(1), 1-25.

Popovic, S. (2018). Research and writing development in the area of sport science publishing in Montenegro. Sport Mont, 16(3), 31-36. https://doi.org/10.26773/smj.181006

Salmon, P. M., \& McLean, S. (2020). Complexity in the beautiful game: implications for football research and practice. Science and Medicine in Football, 4(2), 162-167.

Sergej M. Ostojic. (2021). In Scopus [Profile]. Retrieved December 10, 2021, from https://www.scopus.com/ authid/detail.uri?authorId $=8552029600$

Stevo Popovic. (2021). In Scopus [Profile]. Retrieved December 10, 2021, from https://www.scopus.com/authid/detail. uri?authorId $=55369012200$

Terpstra, J. L., Best, A., Abrams, D. B., \& Moor, G. (2010). Health sciences and health services. In R. Frodeman, J. T. Klein, \& C. Mitcham (Eds.), The Oxford handbook of interdisciplinarity. New York: Oxford University Press.

Yousef Saleh Khader. (2021). In Scopus [Profile]. Retrieved December 10, 2021, from https://www.scopus.com/authid/detail.uri?authorId $=55654192600$ 